\title{
Pengembangan Sistem Navigasi Otomatis Pada UAV (Unmanned Aerial Vehicle) dengan GPS(Global Positioning System) Waypoint
}

\author{
Rahmad Hidayat dan Ronny Mardiyanto \\ Jurusan Teknik Elektro, Fakultas Teknologi Industri, Institut Teknologi Sepuluh Nopember (ITS) \\ Jl. AriefRahman Hakim, Surabaya 60111 \\ e-mail:rahmad14@mhs.ee.its.ac.id, ronny@ee.its.ac.id
}

\begin{abstract}
Abstrak- UAV adalah salah satu wahana tanpa awak di udara yang mana dapat terbang tanpa pilot, menggunakan gaya aerodinamik untuk menghasilkan gaya angkat (lift), dapat terbang secara autonomous atau dioperasikan dengan radio kontrol. UAV digunakan untuk berbagai keperluan baik di lingkup militer maupun sipil. Pada tugas akhir ini dirancang dan direalisasikan pengembangan sistem navigasi otomatis pada UAV dengan GPS waypoint. Sistem ini menggunakan kontrol manual dan autopilot. Pada mode manual, pengguna secara manual mengendalikan pergerakan pesawat melalui radio kontroler sedangkan pada mode autopilot pesawat dikendalikan oleh mikrokontroler Arduino Mega 2560 yang mengolah data-data sensor IMU (Inertial Measurement Unit) yang didalamnya terdapat gyroscope dan accelerometer, GPS dan barometric altimeter sehingga dapat terbang secara otomatis dengan sesuai waypoint GPS yang dimasukkan. Mikrokontroler menerima dan menolah data dari sensor dan menghasilkan keluaran untuk menggerakkan servo aktuator. Pengolahan data dari sensor menggunakan kontrol PID (Proportional Integral Derivative). Pesawat akan terkoneksi dengan ground station melalui perangkat telemetri untuk mengirimkan data penerbangan ke darat. Sistem navigasi ini diharapkan dapat secara tepat mengarahkan pesawat menuju satu titik atau lebih dengan toleransi kesalahan $\leq \mathbf{3 0}$ meter pada ketinggian 30-100 meter. Selain itu pesawat diharapkan dapat terbang dengan radius $\pm 2 \mathrm{~km}$ dari ground station. Hasil dari pengujian dapat dilaksanakan kontrol manual dan otomatis pada UAV melalui 5 channel (aileron, elevator, throttle, rudder dan saklar). Distorsi pada kontrol manual diminimalisir dengan memperbesar faktor pembagi sinyal PWM sebesar 50 $\mu \mathrm{s}-100 \mu \mathrm{s}$. Kontrol otomatis dapat menstabilkan sikap pesawat di udara (sudut roll $45^{\circ}$ dan sudut pitch $30^{\circ}$ ) Setting $\mathrm{Kp} 1,2$ dan Ki 0,01, setting Kp navigasi GPS 0,2 Ki 0,01 dan Kd 4 dengan sudut roll maksimal $15^{\circ}$.
\end{abstract}

Kata Kunci - UAV, Waypoint, PWM, Kontroler PID, sudut pitch, sudut roll.

\section{PENDAHULUAN}

$\mathrm{P}$ ADA Tugas Akhir ini akan dirancang dan direalisasikan sistem navigasi otomatis pada UAV dengan GPS waypoint, dimana mikrokontroler berfungsi sebagai kontroler terbang baik pada mode manual dan otomatis sehingga pesawat dapat terbang sesuai waypoint GPS.

\section{TEORI PENUNJANG}

\section{A. $U A V$}

UAV adalah pesawat yang terbang tanpa operator di dalamnya dan dapat terbang secara autonomous dengan mengolah data dari. UAV dapat dikendalikan secara manual melalui radio kontrol atau secara otomatis dengan mengolah data sensor sehingga dapat terbang sesuai dengan keperluan pengguna.

\section{B. Jenis $U A V$}

Secara umum pembagian jenis UAV dilakukan menurut posisi sayap dan sumber tenaga pesawat.

1) Jenis UAV berdasarkan posisi sayap.

Posisi sayap UAV terbagi dalam 3 bagian, meliputi:

a. High wing. Sayap pesawat berada di atas fuselage.

b. Middle wing. Sayap pesawat berada di tengah fuselage dalam posisi sejajar.

c. Low wing. Sayap pesawat berada di bawah fuselage.

2) Jenis pesawat berdasarkan sumber tenaga penggerak propeller:

a. Combustion engine. Sumber tenaga pesawat menggunakan pembakaran bahan bakar cair pada engine.

b. Elektrik. Sumber tenaga pesawat menggunakan suplai daya dari baterai.

3) Jenis UAV berdasarkan berat meliputi:

a. super heavy. Berat diatas $2000 \mathrm{Kg}$.

b. Heavy. Berat antara $200-2000 \mathrm{Kg}$.

c. Medium. Berat antara $50-200 \mathrm{Kg}$.

d. Light. Berat antara 5-50Kg.

e. Micro. Berat kurang dari $5 \mathrm{Kg}$

\section{Dasar Pergerakan Pesawat}

UAV memiliki 6 derajat kebebasan pergerakan di udara. Meliputi sumbu longitudinal, vertikal dan lateral. Titik pertemuan sumbu-sumbu tersebut merupakan CG (Center of Gravity) dalam kestabilan dan manuver pesawat. Manuver yang dilakukan antara lain:

a. Rolling, gerak pesawat terhadap sumbu longitudinal dengan menggunakan aileron.

b. Pitching, gerak pesawat terhadap sumbu lateral dengan menggunakan elevator.

c. Yawing, gerak pesawat terhadap sumbu vertikal dengan menggunakan rudder.

Gambar 1. Dasar Pergerakan UAV

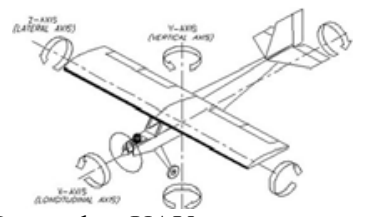

D. Radio Kontrol

Radio kontrol adalah perangkat elektronika yang digunakan untuk mengatur pergerakan UAV. Modul radio kontrol terdiri dari sistem transmiter dan receiver. Transmiter mengirimkan sinyal kontrol menuju receiver melalui channel yang dimiliki secara wireless. 


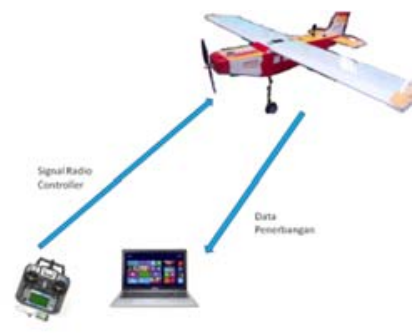

Gambar 2. Pengoperasian UAV

\section{E. Perangkat Elektromekanik UAV}

Perangkat elektromekanik pada UAV dikendalikan oleh sinyal PWM dari receiver. Antara lain sebagai berikut:

a. Motor DC Brushless (BLDC). Adalah motor DC elektrik dengan eksitasi terpisah dan aktif apabila mendapat suplai tegangan searah. Tegangan DC input akan dikonversi menjadi sinyal AC untuk menggerakkan motor. Sinyal kontrol kecepatan pergerakan motor dihasilkan dari receiver.

b. - Electronic Speed Controller (ESC). Adalah perangkat elektronika pengatur kecepatan putar motor BLDC. ESC menerima input pulsa dari receiver dan mengkonversikan pulsa tersebut ke dalam bentuk pengaturan daya yang akan disuplai dari catu daya ke motor BLDC.

c. Motor Servo. Adalah motor elektrik yang bergerak menggunakan suplai tegangan DC. Servo membutuhkan input kontrol berupa PWM untuk memutar motor.

\section{F. Mikrokontroler}

Mikrokontroler berfungsi untuk memproses dan mengolah input data dari receiver dan sensor-sensor untuk menghasilkan output penggerak aktuator. Mikrokontroler yang digunakan adalah Arduino Mega 2560. Arduino Mega 2560 adalah papan mikrokontroler berbasiskan ATmega2560. Arduino Mega 2560 memiliki 54 pin digital input/output, dimana 15 pin dapat digunakan sebagai output PWM, 16 pin sebagai input analog, dan 4 pin sebagai UART (Universal Asynchronous Receiver Transmitter), $16 \mathrm{MHz}$ kristal osilator, koneksi USB, jack power, header ICSP, dan tombol reset.

\section{G. Sensor}

Sensor yang digunakan dalam tugas akhir ini antara lain sebagai berikut:

- GY-85 adalah gabungan dari sensor gyroscope, accelerometer dan magnetometer dengan 3 sumbu axis $\mathrm{X}, \mathrm{Y}$ dan Z. Sensor accelerometer berfungsi untuk menentukan kedudukan benda diam berdasarkan percepatan terhadap gravitasi bumi $\left(9,8 \mathrm{~ms}^{-2}\right)$. Sensor gyroscope berfungsi untuk mengukur kecepatan angular benda bergerak terhadap sumbu axis-nya. Data output sensor dapat diakses melalui komunikasi I2C (Inter-Integrated Circuit) Fast Mode 400kHz. GY85 memiliki sensitivitas 14.375 LSB per $\%$ detik dan pengukuran kecepatan angular maksimum \pm $2000 \%$ detik.

Giroskop berfungsi untuk mengetahui kecepatan angular dari pergerakan suatu benda. Melalui integral pertama terhadap fungsi waktu, nilai kecepatan angular dapat digunakan untuk mendapatkan besar sudut terbentuk dari benda.

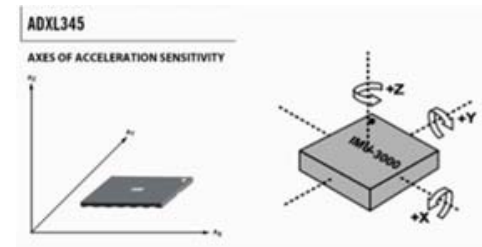

Gambar 6. Sumbu axis giroskop sensor ADXL345

- Sensor Barometrik BMP280.

BMP280 adalah sensor tekanan barometrik dengan range $300 \mathrm{~s} / \mathrm{d} 1100 \mathrm{hPa}$ sampai dengan $2.5 \mathrm{hPa}(1 \mathrm{hPa}=1 \mathrm{mbar})$ atau setara dengan +9000 sampai dengan -500 meter above/below sea level. Sensor ini memiliki tingkat ketelitian hingga $\pm 0.12 \mathrm{hPa}$ (equiv. to $\pm 1 \mathrm{~m}$ ). Ketinggian di permukaan bumi berhubungan dengan tekanan udara. Semakin tinggi ketinggian maka tekanan udara akan semakin rendah. Semakin rendah ketinggian maka tekanan udara akan semakin tinggi.

\section{H. Kestabilan Pesawat}

Pesawat memiliki sudut pitch dan roll hasil filter komplementari sensor accelerometer dan gyroscope. Pada setiap pergerakan di udara, sistem akan merespon perubahan sudut pitch dan roll pesawat terhadap set poin (nilai error). Error kemudian dioleh oleh kontroler PI untuk menghasilkan nilai PWM penggerak servo aileron dan elevator. Pergerakan aileron dan elevator akan memberikan perubahan nilai sudut pitch dan roll pesawat ketika mengudara. Umpan balik plant ini berupa kedudukan pesawat setelah aileron dan elevator berubah.

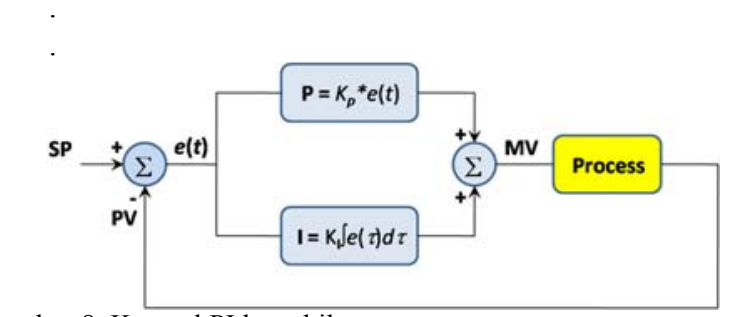

Gambar 8. Kontrol PI kestabilan pesawat

\section{GPS}

GPS adalah adalah sebuah sistem navigasi berbasiskan radio yang menyediakan informasi koordinat posisi, kecepatan, dan waktu, ketinggian dan informasi tambahan lainnya kepada pengguna di seluruh dunia berdasarkan perbedaan garis lintang (latitude) dan garis bujur (longitude). Pengguna hanya membutuhkan GPS receiver untuk dapat mengetahui koordinat lokasi. Keakuratan koordinat lokasi tergantung pada tipe GPS receiver. GPS terdiri dari tiga bagian yaitu satelit pemancar yang mengorbit bumi (Satelit GPS mengelilingi bumi 2 kali sehari), stasiun pengendali dan pemantau di bumi, dan GPS receiver. Untuk menunjukkan koordinat sebuah titik (dua dimensi), alat navigasi memerlukan paling sedikit sinyal dari 3 buah satelit. Untuk menunjukkan data ketinggian sebuah titik (tiga dimensi), diperlukan tambahan sinyal dari 1 buah satelit lagi. Tingkat akurasi GPS ditentukan dengan istilah GDOP (Geometric Dilution of Precision). DOP(Dilution Of Precision) atau GDOP adalah istilah yang digunakan dalam navigasi satelit dan geomatika untuk menentukan efek tambahan geometri satelit navigasi pada 
tingkat kepresisian pengukuran posisi. Ketika satelit GPS yang tertangkap oleh receiver dalam posisi berdekatan di ruang angkasa, maka nilai geometrinya lemah dan nilai DOP tinggi. Saat dalam posisi berjauhan maka nilai geometrinya kuat dan nilai DOP nya rendah.

\begin{tabular}{|c|c|c|}
\hline $\begin{array}{l}\text { Nilai } \\
\text { DOP }\end{array}$ & $\begin{array}{c}\text { Nilai } \\
\text { kepresisian }\end{array}$ & Keterangan \\
\hline$<1$ & ideal & $\begin{array}{l}\text { Level tertinggi tingkat kepresisian GPS } \\
\text { yang digunakan untuk keperluan sistem } \\
\text { performa keakurasian tinggi pada setiap } \\
\text { saat. }\end{array}$ \\
\hline $1-2$ & Excellent & $\begin{array}{l}\text { Level tingkat keakurasian tinggi untuk } \\
\text { sistem aplikasi yang sensitif. }\end{array}$ \\
\hline $2-5$ & good & $\begin{array}{l}\text { Level kepresisian yang sedang. Sering } \\
\text { digunakan untuk keperluan navigasi pada } \\
\text { umumnya. }\end{array}$ \\
\hline $5-10$ & moderate & $\begin{array}{l}\text { Level kepresisian kurang baik tetapi } \\
\text { masih dapat digunakan sebagai } \\
\text { perhitungan. }\end{array}$ \\
\hline $10-20$ & fair & $\begin{array}{l}\text { Level kepresisian yang rendah, hanya } \\
\text { untuk perkiraan posisi. }\end{array}$ \\
\hline$>20$ & poor & $\begin{array}{l}\text { Level kepresisian sangat rendah. } \\
\text { Ketidakakuratan posisi bisa mencapai } \\
300 \mathrm{~m} \text {. }\end{array}$ \\
\hline
\end{tabular}

\section{PERANCANGAN DAN IMPLEMENTASI SISTEM}

\section{A. Arsitektur Sistem}

Perancangan dan implementasi sistem kontrol manualotomatis pesawat mengacu pada blok diagram berikut:

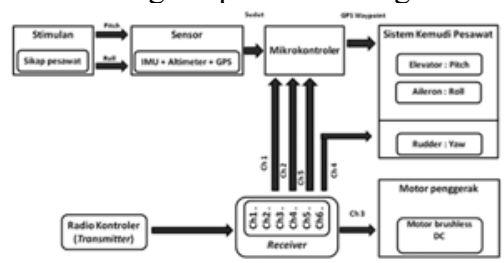

Gambar 9. Blok diagram arsitektur sistem

Pada mode manual, mikrokontroler Arduino Mega 2560 akan melewatkan sinyal PWM dari nano arduino dan merekonstruksi pulsa menggunakan input-output Timer. Ketika mode otomatis diaktifkan, kontroler akan mengolah data sensor-sensor untuk menjaga kestabilan pesawat di udara.

\section{B. Perancangan Hardware}

Perancangan hardware dilaksanakan dengan:

Sinkronisasi radio kontrol dan pergerakan aktuator. Sinkronisasi berfungsi untuk mendapatkan data pergerakan aktuator pesawat terhadap perubahan sinyal PWM.

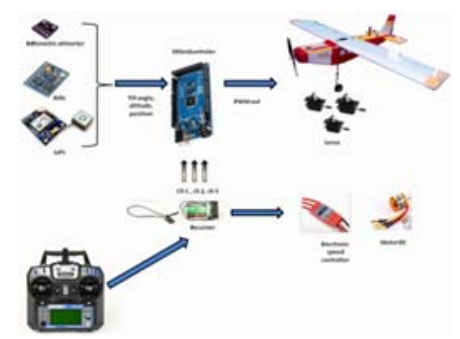

Gambar 10. Perancangan hardware komponen
- $\quad$ Perancangan rangkaian sensor IMU

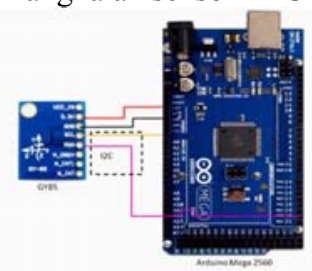

Gambar 11. Koneksi rangkaian GY-85 dan Arduino Mega2560

- Perancangan rangkaian sensor ketinggian

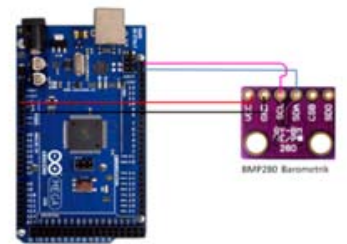

Gambar 12. Koneksi rangkaian BMP280 dan mikrokontroler

- $\quad$ Perancangan rangkaian input PWM

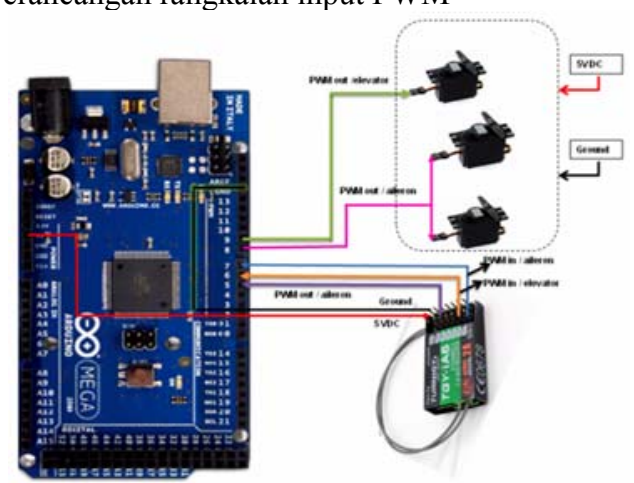

Gambar 13. Koneksi input-output PWM

\section{Perancangan Software}

Perancangan dilakukan untuk mengkoneksikan komponen-komponen elektronik agar sistem dapat berjalan dengan baik. Perancangan meliputi penentuan sudut pitch/roll dan penerimaan input PWM dan pengiriman output PWM.

- Penentuan sudut pitch dan roll

Data dari sensor accelerometer dan gyroscope yang masih berupa raw data masih harus diolah. Raw data dari gyro dan accelerometer dikurangi dengan nilai offset nya. Selanjutnya setelah dikururangi nilai offset, hasil tersebut diubah ke nilai sudut dalam satuan derajat. Output data tersebut masih sangat sensitif terhadap noise seperti getaran dari vibrasi motor brushless. Oleh karena itu digunakanlah suatu metode filtering yaitu dengan menggunakan complementary filter. Complementary filter adalah suatu metode filter yang merupakan penggabungan antara LPF (Low Pass Filter) dan HPF (High Pass Filter).

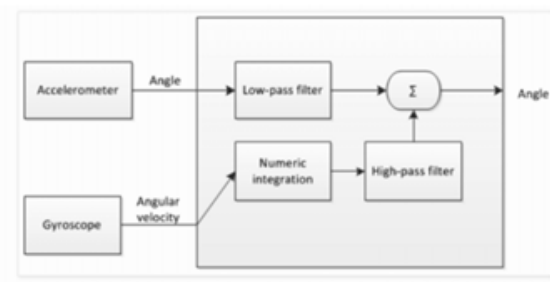

Gambar 14. Penentuan sudut pitch dan roll dengan Complementary Filter 
- $\quad$ Penerimaan input dan output PWM

Mikrokontroler Arduino Mega menerima sinyal PWM dari receiver. Pembacaan signal PWM dari receiver tersebut dengan memasukkan input PWM channel 1, channel 2 dan channel 5 ke pin PWM 7,6 dan 5. Untuk mengkomunikasikan antara servo aktuator dengan dengan mikrikontroler maka dibuatlah program sebagai attachment servo terhadap sistem kontrol yaitu PWM out pitch pada pin 9 dan PWM out roll pada pin 8.

\section{Desain Kontroler PI pada Sistem Kestabilan}

Algoritma kontrol proporsional integral pada sistem kestabilan pesawat meliputi sudut pitch dan roll. Desain kontroler PI digunakan ketika mode otomatis diaktifkan. Pada kontrol kestabilan pesawat di udara, set point kontroler PI menggunakan referensi sudut nol pitch dan roll. Apabila terjadi perubahan kemiringan pada saat pesawat mengudara, akan menghasilkan error pitch dan roll. Error tersebut kemudian diproses pada kontroler, sehingga menghasilkan sinyal PWM untuk menggerakkan aileron atau elevator. Pergerakan aileron atau elevator akan memberikan kompensasi terhadap kemiringan pesawat, sehingga diharapkan sudut pitch dan roll bernilai nol (pesawat terbang lurus dan stabil).

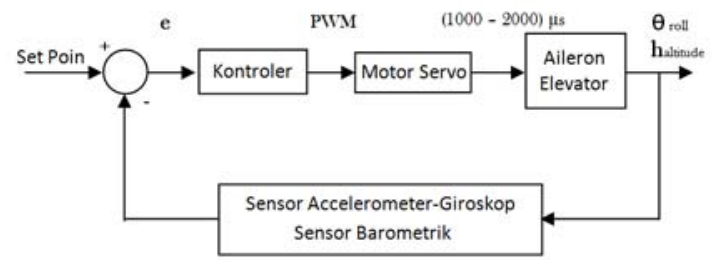

Gambar 15. Desain kontrol PI kestabilan pesawat di udara

\section{E. Desain Kontroler Proporsional-Integral-Derivatif pada Navigasi menggunakan GPS Waypoint}

Dalam perancangan Tugas Akhir ini jumlah satelit minimal yang dibutuhkan untuk menjalankan mode navigasi otomatis adalah sebanyak 8 satelit. Untuk menentukan arah(heading) pesawat terhadap $0^{\circ}$ (arah utara) maka diguanakanlah fungsi program turunan dari posisi GPS. Heading pesawat didapat pada saat pesawat mengalami perpindahan posisi (latitude dan longitude). Sudut dan jarak estimasi dari titik awal ke titik tujuan didapat dari perbedaan posisi awal dan titik latitude-longitude tujuan yang aka dituju. Dengan demikian maka didapatkan setpoint arah ke waypoint yang diinginkan. Perbedaan besaran derajat antara sudut ke tujuan dan arah heading saat ini didefinisan sebagai error arah waypoint. Selanjutnya nilai error tersebut digunakan untuk pengaturan sistem agar pesawat dapat membelok sesuai sudut pesawat ke tujuan. Pada sistem pesawat, nilai output dari kontrol proporsinal-derivatif diimplementasikan pada pengaturan sudut aileron.

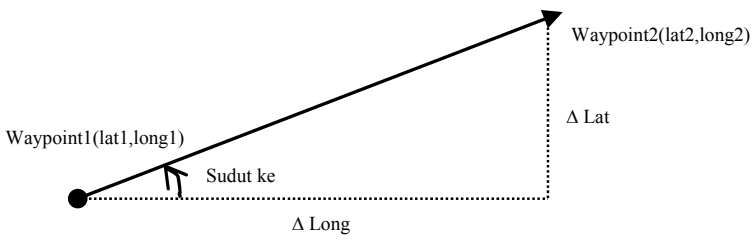

Gambar 16. Sketsa perhitungan penentuan jarak dan sudut ke tujuan

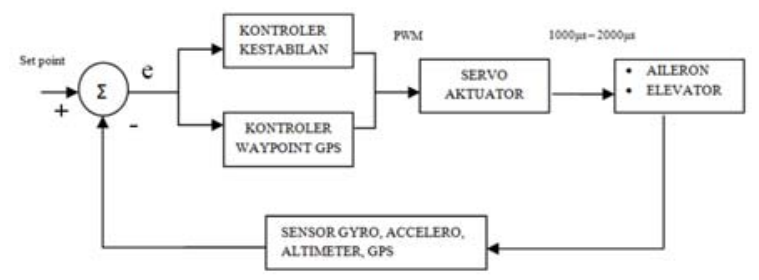

Gambar 17. Desain kontrol PI sistem navigasi GPS waypoint

\section{PENGUJIAN DAN ANALISA SISTEM}

Pada pengujian dan analisa sistem dibahas mengenai pengujian parsial input sinyal PWM, pengujian sistem kestabilan pesawat dan pengujian kontrol ketinggian Pengujian keseleruhan dilaksanakan pada sistem navigasi otomastis dengan GPS waypoint pada UAV yang merupakan gabungan kontrol kestabilan dengan kontrol navigasi.

\section{A. Pengujian Parsial}

1) Pengujian Sinyal PWM pada Mikrokontroler

Pengujian sinyal PWM dilaksanakan dengan membaca nilai PWM dalam spesifikasi time high $(\mathrm{t}$ on) pada setiap channel radio kontrol. Pengujian dilaksanakan pada saat nilai PWM minimum, nilai tengah dan nilai maksimum. Nilai tengah rata-rata dari channel 1,2,3,4 adalah 1500 us. Nilai PWM minimum rata-rata adalah 1000 us dan nilai PWM maksimumnya adalah 2000 us. Nilai PWM pada saat idle (control stick) tidak bergerak mempunyai sedikit pergeseran kurang lebih berkisar antara 1 sampai dengan 30 us. Hal ini mengakibatkan getaran kecil (glitch) pada servo aktuator.

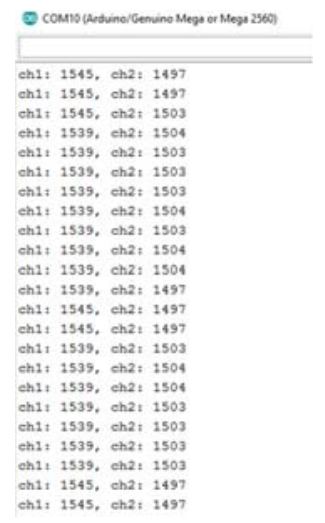

Gambar 18. Hasil pembacaan nilai tengah PWM

2) Pengujian kontrol stabilitas pesawat

Pengujian ini dimaksudkan untuk mengetahui respon kontrol stabilitas pesawat di udara berdasarkan gerakan pitching dan rolling. Gerakan pitching yang dihasilkan merupakan respon dari error sudut terhadap setpoint sudut $0^{\circ}$ pitch dari IMU. Sedangkan gerakan rolling merupakan respon dari error sudut terhadap setpoint $0^{\circ}$ roll. Respon kontrol pada kontrol stabilitas pesawat merupakan hasil dari pengolahan sudut accelerometer dipadukan dengan kecepatan sudut gyroscope dengan menggunakan complementary filter. kesalahan pada pembacaan sudut sensor yang terpasang pada sub-sistem menggunakan Complementary Filter. Pengujian dilakukan dengan melihat respon sudut output Complementary Filter terhadap perubahan posisi yang telah ditentukan, meliputi posisi pitching dan rolling. 

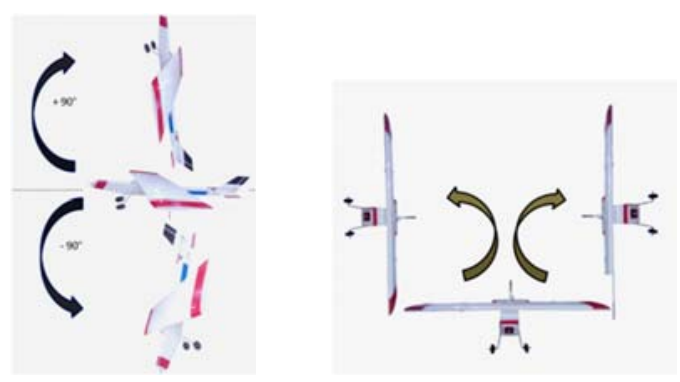

Gambar 19. Pengujian Posisi pitching dan rolling pesawat

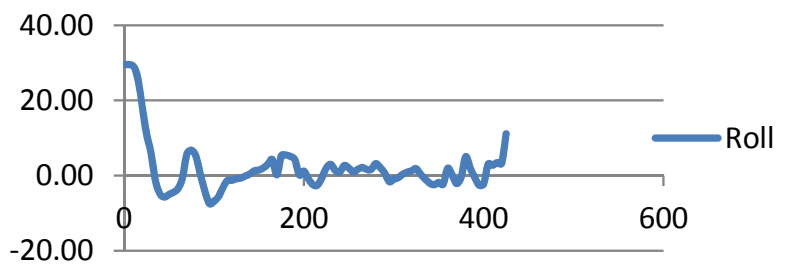

Gambar 20. Grafik kontrol rolling pesawat

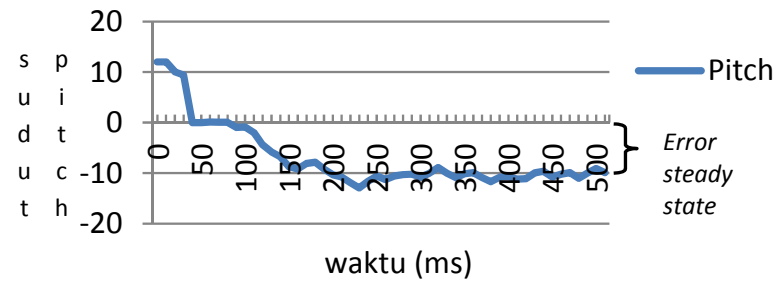

\section{B. Pengujian kontrol Stabilitas Ketinggian}

Pengujian kontrol stabilitas ketinggian secara parsial dilaksanakan dengan menaikkan dan menurunkan ketinggian pesawat. Setpoint ketinggian adalah ketinggian dari sensor barometrik altimeter pada saat nilai PWM channel 5 lebih dari 1500 us. Pada saat ketinggian pesawat bertambah maka nilai error ketinggiannya bernilai negatif sedangkan pada saat ketinggian pesawat menurun maka nilai error nya bernilai positif. Selanjutnya nilai error tersebut digunakan sebagai input kontrol ketinggian dengan dikalikan dengan konstanta proporsionalnya (Kp) sehingga menghasilkan aksi kontrol yang terhadap sudut pitch (elevator).

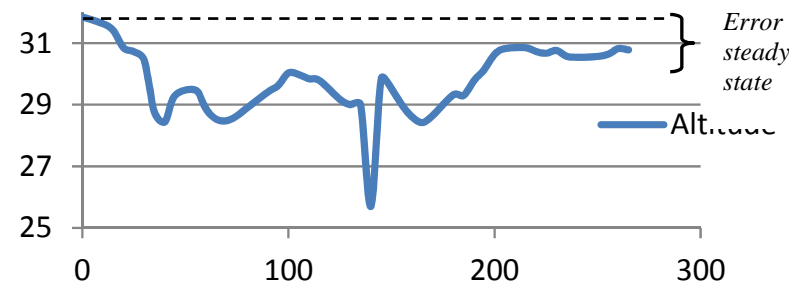

Gambar 21. Grafik kontrol ketinggian

\section{Pengujian Integrasi}

1) Pengujian Kontrol Stabilitas Pesawat

Pengujian dilaksanakan dengan melihat respon sistem kestabilan terhadap nilain $\mathrm{Kp}$ dan $\mathrm{Ki}$ baik kontrol pitch maupun roll. Pada nilai Kp pitch sebesar 2 dan dan Kp roll sebesar 1 didapatkan hasil bahwa kontrol pitch terlalu overshoot sehingga pergerakan pitch tidak halus sehingga respon pesawat berosilasi. Nilai $\mathrm{Kp}$ pitch yang paling mendekati sempurna adalah sebesar 1,2 sedangkan nilai $\mathrm{Ki}$ pitch dan roll sebesar 0,01. Berikut gambar tebel pengujian sudut pitching, sudut rolling nilai gain Kp yang berbeda.

Tabel 4.1 Tabel penentuan nilai Kp pitch

\begin{tabular}{ccll}
\hline \hline No & Nilai Kp Pitch & Respon Pesawat & \\
\hline 1 & 2 & $\begin{array}{l}\text { Pesawat seperti lumba-lumba } \\
\text { (berosilasi) }\end{array}$ \\
2 & 1,7 & $\begin{array}{l}\text { Pesawat berosilasi pada high speed } \\
\text { stabil pada low speed } \\
\text { Osilasi pada highspeed medium,stabil } \\
\text { pada low speed } \\
\text { Osilasi pitch pada high speed dan low } \\
\text { speed kecil }\end{array}$ \\
\hline \hline
\end{tabular}

\section{2) B.2. Pengujian Kontrol Navigasi Otomatis GPS} waypoint

Pengujian kontrol navigasi GPS secara parsial dilaksanakan dengan terlebih dahulu menginputkan waypoint tujuan (latitude longitude). Setelah signal GPS valid dan jumlah satelit yang tertangkap lebih dari 8 maka kontroler akan menjalankan kontrol navigasi otomatis dengan mengarah waypoint yang akan dituju. Output kontrol dari navigasi GPS diaktualisasikan terhadap perubahan sudut aileron. Kontrol navigasi GPS menggunakan kontrol proporsional dan derivatif. Perbedaan arah heading pesawat dengan course ke waypoint tujuan dinamakan error bearing. Error ini sebagai bahan dasar kontrol pada navigasi GPS. Berikut hasil pengujian pada kontrol navigasi GPS:

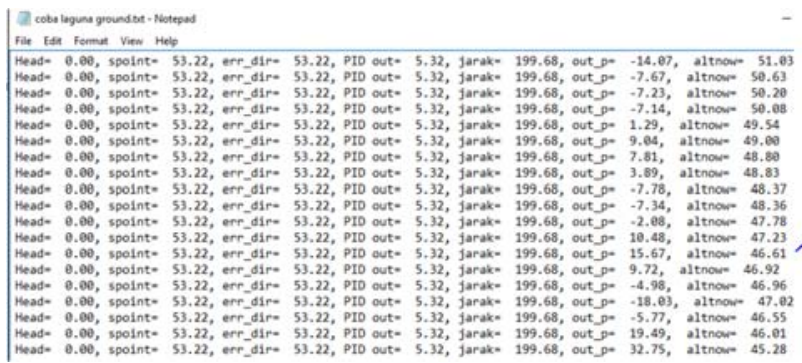

Gambar 22. Grafik kontrol navigasi otomatis GPS waypoint

\section{KESIMPULAN/RINGKASAN}

Berdasarkan data hasil uji terbang sistem kontrol otomatis baik kestabilan di udara dan navigasi GPS waypoint pada pergerakan UAV ini diperoleh beberapa kesimpulan antara lain sebagai berikut:

1. Kontrol manual dan otomatis pada UAV menggunakan modul mikrokontroler Arduino Mega 2560 dapat dilaksanakan menggunakan 3 channel (aileron, elevator, dan saklar) sedangkan 2 channel(throttle dan rudder) menggunakan receiver radio kontrol.

2. Konversi sinyal PWM dari receiver pada kontrol manual terdapat glitch sebagai dampak dari tidak stabilnya signal PWM. Upaya untuk memperhalus output gerakan servo dapat dilakukan dengan memperbesar faktor pembagi signal PWM yang diterima sebesar 50 us sehingga faktor ketidakstabilan PWM tidak terlalu berpengaruh.

3. Kontrol sistem kestabilan pesawat di udara didapat kan dengan pengolahan sensor gyroscope dan accelerometer dengan metode Complementary Filter dengan nilai alpha 0,05 memberikan respon yang efektif. 
4. Pengujian terbang kontrol otomatis kestabilan pesawat di udara dapat dilaksanakan dengan nilai gain Kp pitching dan rolling ideal diperoleh pada 1,2 dan 1 dan Ki pitch dan roll masing-masing sebesar 0,01 .

5. Pengujian kontrol ketinggian otomatis pesawat di udara dapat dilaksanakan dengan baik dengan nilai Kp 14.

\section{DAFTAR PUSTAKA}

[1] PORDIRGA AEROMODELLING PB FASI, "Buku Panduan Aeromodelling Indonesia", Jakarta, 2009.

[2] Elizabeth Bone. "Unmanned Aerial Vehicles: Background and Issues for Congress". Congressional Research Service, Washington, DC. 2003.

[3] GNU, Libraries and tutorials for Arduino IMU processing, diakses pada tanggal 1 Pebruari 2016, http://www.tkjelectronics.com/.

[4] HaiYang Chao, YongCan Cao and YangQuan Chen," Autoplots for Small Unmanned Aerial Vehicles: A Survey", 2010

[5] Ippolito Corey, "An Autonomous Autopilot Control System Design for Small-Scale UAV's”, QSS Group, Inc. NASA Ames Research Center, 2012

[6] Ogata, katsuhiko, Edi Laksono (Penterjemah). 1993. Teknik Kontrol Automatik (Sistem Pengaturan) Jilid 2. Jakarta : Erlangga

[7] Antono Djodi, "Motor DC Brushless Tiga Fase-Satu Kutub", Teknik Elektro Politeknik Negeri Semarang, Semarang, 2012

[8] Understanding PWM, diakses pada tanggal 12 Desember 2014, http://ebldc.com/?p=48

[9] Geoffrey Blewitt, "Basics of the GPS Technique: Observation Equations", Department of Geomatics, University of Newcastle Newcastle upon Tyne, NE1 7RU, United Kingdom, 1997.

[10] Dasar-Dasar Autopilot atau Flight Controller,diakses pada tanggal 7 Maret 2016, http://aeroengineering.co.id/.

[11] Pesawat Tanpa Awak, Unmanned Aerial Vehicle (UAV), diakses tanggal 8 Maret 2016, http://zonaelektro.net/.

[12] Products Engines for Various Size Tactical UAVs, diakses tanggal 9 Maret 2016, http://www.uavenginesltd.co.uk/products/.

[13] Theodore A. Talay,"Introduction to the Aerodynamics of Flight", National Aeronautics and Space Administration, Washington, D.C. 1975.

[14] Adverse Yaw and Aircraft Turns, diakses pada tanggal 15 Juni 2016,

[15] http://www.aerospaceweb.org/question/dynamics/q0045.shtml.. 